\title{
COLEÇÕES BIOLÓGICAS E BIBLIOTECAS UNIVERSITÁRIAS: UMA PROPOSTA PARA ALÉM DO DESENVOLVIMENTO SUSTENTÁVEL
}

\author{
BIOLOGICAL COLLECTIONS AND ACADEMIC \\ LIBRARIES: A PROPOSAL BEYOND SUSTAINABLE \\ DEVELOPMENT
}

\author{
Marcos Felipe Gonçalves Maia ${ }^{a}$ \\ Rodney Haulien Oliveira Viana ${ }^{b}$
}

\begin{abstract}
RESUMO
Introdução: O ambientalismo e a ecologia têm ganhado espaço nas discussões e nas práticas cotidianas das bibliotecas universitárias.

Objetivo: descrever a importância da integração dos metadados dos registros das coleções biológicas nos catálogos das bibliotecas da Universidade Federal do Tocantins (UFT) como uma ação "ambientalmente contextualizada", para além do desenvolvimento sustentável.

Metodologia: Pesquisa descritivo-explicativa, com abordagem qualitativa, com coleta de dados por meio de pesquisas bibliográfica e documental. Leitura teórica por meio do desconstrucionismo de Jacques Derrida.

Resultados: Os conceitos de desenvolvimento sustentável, sustentabilidade institucional e ecologia da informação têm sido usados pelos profissionais da informação de uma maneira acrítica, sem considerar sua perspectiva mercadológica e para manutenção do sistema de exploração da natureza.

Conclusões: se os profissionais da informação intentam participar da preocupação pela natureza devem estar atentos para desenvolverem ações para além do desenvolvimento sustentável. Devem ajudar no processo de construção de saberes locais e ajudar na construção de modos de utilização da informação por meio de suas práticas cotidianas.
\end{abstract}

Descritores: Biologia. Biblioteca universitária. Catálogos. Metadados. Organização da Informação.

\footnotetext{
${ }^{a}$ Mestre em Educação pela Universidade Federal do Tocantins. E-mail: marcosmaia@uft.edu.br ${ }^{b}$ Doutor em Botânica pela Universidade Federal de Viçosa. Professor da Universidade Federal do Tocantins. E-mail: rodney@uft.edu.br
} 


\section{INTRODUÇÃO}

Ao olharmos para trás, em especial para os últimos cinquenta anos da humanidade, poderemos encontrar o princípio de uma inquietação: a relação entre humanidade e natureza. Não que essa relação nunca tivera sido pensada ou questionada. Até porque os filósofos gregos naturalistas, há quase três mil anos, pensaram bastante sobre essa relação e sobre o "material/elemento" que teria sido a origem de tudo: água, ar, ou o quê? Os povos orientais também tiveram uma íntima relação com a natureza, em especial com a interdependência de tudo e de todos. Entretanto, queremos chamar atenção para outro tipo de olhar para a natureza: a sua exploração para o crescimento e riqueza das nações. Nesse cenário, as bibliotecas, inclusive as universitárias, têm se preocupado com a inter-relação entre instituições e a natureza e sua exploração/preservação (LOZANO; ZAFALON; COSTA, 2009; PAYNE et al., 2007; VIEIRA, 1980, 1992).

A Universidade Federal do Tocantins (UFT) possui oito bibliotecas em sete campi. Está em fase de implantação do Repositório Institucional e da Biblioteca Digital de Teses e Dissertações. Frente a isso e à atuação em projetos ditos ecológicos, uma pergunta perpassa nossa investigação: o que é desenvolvimento sustentável, sustentabilidade institucional e ecologia da informação e como a biblioteca universitária pode atuar nesse cenário?

Aline Azevêdo (1992) falando das coleções do Museu Paraense Emílio Goeldi destaca que os profissionais da informação devem ficar atentos para a importância de se trabalhar com tratamento de dados que não sejam necessariamente bibliográficos como um enfrentamento e um desafio profissional. Assim, este trabalho objetiva descrever a importância da integração dos metadados dos registros das coleções biológicas nos catálogos das bibliotecas da Universidade Federal do Tocantins (UFT) como uma ação "ambientalmente contextualizada", para além do desenvolvimento sustentável. Entendemos uma ação "ambientalmente contextualizada" qualquer ação, processo ou atividade que esteja vinculada à conservação/preservação da natureza. 
Pode-se dessa maneira atingir duas finalidades: ajudar no processo de disseminação da informação produzida localmente (pelas coleções biológicas) e atender a uma necessidade de promoção de práticas ambientais para além do desenvolvimento sustentável, sendo que este, conforme veremos a seguir, possui uma vertente economicista e não um foco na preservação da natureza.

Esta é uma pesquisa descritivo-explicativa de abordagem qualitativa com procedimento de coleta e análise de dados por meio de pesquisa bibliográfica e documental (BOGDAN; BIKLEN, 2006). A pesquisa bibliográfica, de acordo com Telma Lima e Regina Mioto (2007, p. 44), é importante "para fundamentar teoricamente o objeto de estudo, contribuindo com elementos que subsidiam a análise futura dos dados obtidos"; e a pesquisa documental "propõe-se a produzir novos conhecimentos, criar novas formas de compreender os fenômenos e dar a conhecer a forma como estes têm sido desenvolvidos." (SÁ-SILVA; ALMEIDA; GUINDANI, 2009, p. 14).

Foram levantadas na literatura experiências que os/as bibliotecários/as vem desenvolvendo frente ao fenômeno do "desenvolvimento sustentável" e da "função/missão" da biblioteca universitária na coleta/organização e disseminação da informação; bem como a definição dos conceitos de desenvolvimento sustentável, sustentabilidade institucional e ecologia da informação. Foram identificadas as coleções biológicas existentes na Universidade Federal do Tocantins e seus respectivos documentos de criação. Com isso foi feita uma argumentação da possibilidade de integração dos metadados dos registros dessas coleções nos catálogos das oito bibliotecas da supracitada universidade a fim de divulgar e promover estudos científicos e sua popularização à comunidade acadêmica na perspectiva da conservação da natureza e não da exploração do "meio ambiente" e manutenção do sistema econômico vigente.

Para tal análise foi feita uma "leitura atenta", proposta pelo método desconstrutivista de Jacques Derrida, dos conceitos de "desenvolvimento sustentável", "sustentabilidade institucional" e "ecologia da informação" encontrados no estado da arte apreendido. Essa desconstrução é um tipo de operação intelectual para deslocar e relativizar os conceitos, desmontando os 
textos e apresentando seus significados, inclusive os latentes (GOULART, 2003).

\section{SUSTENTABILIDADE, DESENVOLVIMENTO E ECOLOGIA DA INFORMAÇÃO: POR UMA CRÍTICA DAS IDEIAS}

$\mathrm{Na}$ história da acumulação das riquezas das nações a exploração da natureza foi uma prática comum. Porém, com o passar dos anos aqueles recursos, em sua maioria não-renováveis, estão sendo esgotados. E os que poderiam se renovar, porém com um tempo diferente da ganância humana, não o conseguem. Frente essa realidade, a partir da década de 1960/1970 a humanidade começa a criar espaços públicos de discussão sobre o uso desses recursos.

Com as reuniões preparativas para a Conferência das Nações Unidas sobre Meio ambiente Humano surgiu o debate da sustentabilidade. A conferência foi então realizada em 1972, em Estocolmo na Suécia, e de lá pra cá esse tema ganhou visibilidade. Naquele ano, diversos países, com também diversos interesses, muitos contraditórios entre si, decidiram por um "conceito intermediário" sobre o que seria um "ecodesenvolvimento" (COSTA, 2008; VIEIRA, 1992).

Quinze anos depois dessa conferência, mas ainda antes da Rio 92, a Organização das Nações Unidas lança o relatório Brundtland. Esse relatório cunhou a expressão "desenvolvimento sustentável" para designar o processo de mudança em que o uso dos recursos e o crescimento econômico deve ampliar $\mathrm{o}$ atendimento às necessidades humanas presentes e futuras. Esse relatório reconhece que os problemas ambientais advêm das relações desiguais entre as nações e argumenta que o desenvolvimento sustentável só é possível com a alteração do sistema econômico vigente e com a erradicação da pobreza (VIEIRA, 1992).

Tentando mascarar a atitude exploratória da natureza, desenvolvimento sustentável tem sido entendido como sendo o desenvolvimento que satisfaz as necessidades do presente sem comprometer a habilidade de gerações futuras 
de satisfazer suas próprias necessidades (BRUNDTLAND, 1987).

De acordo com Agenda 21, sustentabilidade possui 4 dimensões: social, econômica, ambiental e institucional. Enquanto a dimensão ambiental é claramente definida como a soma de todos os processos bio-geológicos, as outras dimensões não são tão fáceis assim de serem definidas (SPANGENBERG; PFAHL; DELLER, 2002). Já para Ignacy Sachs (apud COSTA, 2008, p. 88) a sustentabilidade possui cinco dimensões: social, econômica, ecológica, espacial e cultural. Estes deveriam ser considerados em conjunto em todo planejamento de desenvolvimento.

$\mathrm{Na}$ visão de sustentabilidade da Agenda 21, como vimos acima, a sustentabilidade possuiria uma participação institucional. Esta palavra, mesmo para as Ciências Sociais, não tem sido facilmente compreendida, ou pelo menos tem sido amplamente debatida.

Não há consenso sobre a definição do que vem a ser sustentabilidade institucional. Em uma revisão da literatura mundial são apresentados cinco grandes definições para essa expressão: 1 - continuação do fluxo de benefícios para os usuários/clientes; 2 - a longevidade da instituição; 3 - habilidade da organização de encontrar recorrentes financiamentos; 4 - capacidade de uma instituição de gerar um nível mínimo de produtos e serviços valorizados em longo termo e 5 - produção e manutenção de resultados desejados para atender/satisfazer objetivos coletivos (KAYAGA; MUGABI; KINGDOM, 2013). Os autores fazem uma releitura de suas pesquisas, e em especial se valendo das definições apresentadas nos itens 4 e 5 , elaboram um conceito de sustentabilidade institucional: "a capacidade de instituições continuamente gerarem um nível mínimo e de qualidade de saídas (outputs) valorizadas, e de priorizar aprendizado para o aprimoramento contínuo." (KAYAGA; MUGABI; KINGDOM, 2013, p. 17).

Falando a respeito das dificuldades de se adaptar ao meio e às ameaças, Sebastião Teixeira (2016) define sustentabilidade institucional como sendo "o grau de utilidade com que a organização é percebida pela sociedade ou por segmentos dessa sociedade". Esta definição reforça a visibilidade da instituição frente à sociedade. Mas o que é uma instituição? 
Seu conceito também não é homogêneo. Spangenberg, Pfahl e Deller (2002). Entendem instituição como o sistema de regras que governam as relações dos membros de uma sociedade. Assim, instituição é entendida como um sistema de regras. O mesmo pode ser visto em Kayaga, Mugabi e Kingdom (2013, p. 16) ao definirem instituição como conjunto de "regras e papeis pelos quais a tomada de decisão e a implementação é estruturada, i. e., instituições como a combinação de organizações (bem como atores), mecanismos e orientações institucionais".

Já para Johnson e Wilson (2000, p. 302) o conceito de sustentabilidade institucional se integra ao de instituição ao definir aquela como sendo "o conjunto de normas, valores e práticas que podem ser estabelecidas durante 0 curso de intervenções e que podem ativar ações e resultados que continuam para além das intervenções provocadas". Conceitos que se aproximam das definições de Mathias (2001) e do capital social de Robert Putman (2005).

Em todas as definições acima de sustentabilidade institucional é possível perceber a possibilidade de manutenção e sobrevivência de uma empresa, instituição, ou órgão público, já que, seja qual for a tipologia de instituição, o foco é ser sustentável. Entretanto, uma indagação se apresenta: o que é ser sustentável? Vimos acima que a resposta parece óbvia: ser sustentável é permanecer, é continuar. Continuar o quê? A exploração da natureza?

Heloísa Costa (2008) chama atenção para três pontos importantes nessa temática: o desenvolvimento de países de "primeiro mundo" se deu com a exploração dos recursos naturais, mas hoje em dia, os que estão em fase de desenvolvimento não podem mais se valer desses recursos; essa relação norte-sul acaba dando os limites e as possibilidades da sustentabilidade. $O$ segundo ponto diz respeito as diversidades de opiniões presentes na Conferência de Estocolmo em 1972: seu resultado tentou ser um caminho do meio (divergências ainda hoje não superadas!). O terceiro ponto se refere à pretensa relação dada ao crescimento populacional como fator preponderante sobre os recursos naturais. Conforme o próprio relatório Brundtland mostrou esse crescimento populacional não é o fator desencadeante das ameaças à natureza, mas antes a exploração exacerbada e a má distribuição das 
riquezas. A quem interessa esse debate?

"O que é evidente é que todo esse debate em torno da eco escassez, limites naturais, superpopulação e sustentabilidade é um debate sobre a preservação de uma ordem social específica e não um debate acerca da preservação da natureza em si" (HARVEY apud COSTA, 2008, p. 83).

Com o discurso de proteção do "meio ambiente" a racionalidade econômica na verdade tem protegido o modo vigente de produção de riquezas, na verdade de desigualdades. Com a "promessa" de cuidado do meio ambiente, está na verdade protegendo o capitalismo. Isso quer dizer que a natureza já não existe mais nem física, porque fora explorada, nem simbolicamente, porque de natureza vira "meio ambiente". Assim, "meio ambiente compreende uma visão de natureza da perspectiva do sistema urbano-industrial. Tudo que é relevante para o funcionamento deste sistema torna-se parte do meio ambiente" $O$ ser humano é o agente dessa conceituação e a natureza tem apenas um papel secundarizado (COSTA, 2008, p. 96).

Com a falsa ideia de modernização e progresso, essa forma de "desenvolvimento sustentável" é na verdade uma recolonização (PORTOGONÇALVES, 2006). Marca-se o que é o ideal, o ser desenvolvido e força-se a construção, a exploração e o crescimento para se igualar a um padrão dito 0 bom, o melhor.

Uma nova geopolítica vem sendo gestada onde o meio ambiente vem se constituindo na espinha dorsal. [... essa geopolítica] da biodiversidade $e$ do desenvolvimento sustentável não só prolonga e intensifica os anteriores processos de apropriação destrutiva dos recursos naturais como, ao se configurar no contexto de uma globalização econômica, leva à desnaturalização da natureza [...] e, com o discurso do desenvolvimento sustentável, promove uma estratégia de apropriação que busca naturalizar - dar carta de naturalização - a mercantilização da natureza. Nessa perversão do natural é que se jogam as controvérsias entre a economização da natureza e a ecologização da economia (PORTO-GONÇALVES, 2006, p. 451)

Assim, desenvolvimento é "des-envolver". É sair do envolvido, do 
próximo e da realidade local para o universal, para a pretensa proposta de racionalidade universal em tudo da modernidade falida. Isto apaga a diversidade com a desejada igualdade. Ruim para a própria humanidade e para a natureza já que "a diferença, a diversidade, talvez o maior patrimônio que a humanidade tenha" está sendo ameaçada (PORTO-GONÇALVES, 2006, p. $64)$.

O conceito de ecologia se insere nessa perspectiva da diversidade. No final da década de 1870 o zoologista alemão Ernst Haeckel cunhou o termo "ecologia" com a junção de duas palavras gregas oikos + logos, dando-lhes o sentido de relação dos animais com os ambientes orgânicos e inorgânicos na sua diversidade. Atualmente, ecologia é então entendida como o estudo das relações entre organismos e seus ambientes; num nível expandido de ecologia seriam agregados os problemas sociológicos e políticos da humanidade tais como crescimento populacional, escassez de comida, poluição e aquecimento global (ECOLOGY, 2016; LAROCA, 1995).

Tomando o conceito de ecologia como inspiração metafórica, Thomas Davenport (1998) desenvolve o conceito de "ecologia da informação". Sua preocupação era a busca de um conceito ecológico para o gerenciamento da informação. Para ele informação é um termo complexo que agrega os conceitos de "dados" e "conhecimento", numa perspectiva de interpretação e significação para a humanidade. Assim, ecologia da informação seria, para Davenport (1998), uma abordagem holística da informação com quatro atributos chave: 1) integração dos diversos tipos de informação; 2) reconhecimento de mudanças evolutivas; 3) ênfase na observação e na descrição e 4) ênfase no comportamento pessoal e informacional.

Essa abordagem, apesar de possuir um foco no mercado para o bom desempenho da instituição gerencial, tenta apreender dos fenômenos ecológicos a transformação do olhar para o gerenciamento da informação. Isto é, para Davenport (1998) não adianta dar acesso à informação sem saber o que o usuário fará com ela, assim, "uma ação ou iniciativa gerencial que não altera o comportamento informacional, não vale a pena colocá-la em prática" (DAVENPORT, 1998, p. 50). 
A abordagem de Thomas Davenport (1998) é marcadamente mercadológica. Entretanto, dentre as abordagens que trazem a "ideia" de natureza, ou aproximação a esta, a ecologia da informação é a única que tenta aprender com o modo de funcionamento dos ecossistemas e das relações entre todos os seres vivos, orgânicos e inorgânicos. Aprender com a natureza e tentar reproduzir nas organizações pode ser proveitoso para as práticas dos profissionais da informação, mas sempre se perguntando: a quem interessa e por que interessa tal assunto?

\section{BIBLIOTECA UNIVERSITÁRIA E AS QUESTÕES DA NATUREZA: UM OLHAR PARA A UNIVERSIDADE FEDERAL DO TOCANTINS E SUAS COLEÇÕES BIOLÓGICAS}

Com a inspiração de colaborar com o meio ambiente algumas bibliotecas no Brasil e em outros países têm desenvolvido práticas ambientalmente contextualizadas.

Diversas bibliotecas universitárias do Reino Unido desenvolveram "iniciativas verdes" a fim de ajudar com o "futuro do planeta". Atividades tais como: redução do lixo, reaproveitamento de papel e outros objetos de diversos materiais, bem como atividades educativas foram realizadas com intuito de fazer a diferença (PAYNE et al., 2007, passim).

No Brasil, Lozano, Zafalon e Costa (2009) apresentam um relato de atuação de bibliotecários num processo de educação ambiental na Universidade Federal de São Carlos (UFSCAR) como facilitadores no gerenciamento de resíduos químicos por meio de processos educativos e de disseminação da informação. Nathalice Cardoso (2010) destaca três projetos de atuações de bibliotecários/bibliotecas no cuidado de o meio ambiente: desde venda de latinhas para compra de livros, reaproveitamento de lixo até contação de histórias em trilhas ecológicas. O estudo de Cardoso (2010, p. 158) conclui que o bibliotecário, no campo ambiental, deve "disseminar a informação ambiental e colocar em prática suas habilidades e competências como educador, visando à conscientização ambiental da comunidade para uma 
melhor qualidade de vida"

Visando ao desenvolvimento harmônico e sustentável da Amazônia, Bellesi e Silva (1992) apresentam o sistema de informação da Amazônia (SIAMAZ) destacando sua importância para o intercâmbio de informações entre os países amazônicos.

Em todos esses relatos de desenvolvimento sustentável apoiado pelas bibliotecas não aparece a crítica a esse conceito: sem a percepção da sua forte vinculação à manutenção de uma ordem social vigente. Teria a biblioteca universitária, então, a função de manter a ordem social vigente? Se não, qual seria então a missão da biblioteca, em especial, a universitária?

Reexaminando o conceito de biblioteca universitária, o professor Murilo Cunha (2010) afirma que sua missão continua sendo "proporcionar acesso ao conhecimento" de maneira a propiciar a aprendizagem da comunidade acadêmica ao longo da vida de seus alunos, professores e pesquisadores. Para além disso, Sílvia Castrillon (2009) argumenta que a biblioteca deve atuar na construção de seres humanos autônomos e partícipes de sua realidade social, transformando-as, se for necessário.

Assim, é de suma importância que a biblioteca universitária seja capaz de propiciar acesso às informações para o auxílio da construção de saberes e conhecimentos para a compreensão das reais necessidades ambientais, naturais e locais. De acordo com David Lankes (2012), ao abrir mão da ânsia angustiante de colecionar tudo com a finalidade universalizante, a biblioteca (inclusive a universitária, bem como sua homóloga biblioteca escolar) deve olhar para as construções de saberes locais e de suas comunidades; o que também é corroborado por Marcos Maia e Larissa Santos (2015).

A convivência com a natureza nos proporcionou "um saber próprio forjado no contato com aquele ecossistema, que deve ser incorporado e considerado enquanto um patrimônio da humanidade na sua especificidade"; devemos valorizar "o saber com e não, simplesmente, o saber sobre que, sempre, se quer universal e assim se desloca das especificidades do contato com a vida" (PORTO-GONÇALVES, 2006, p. 456, grifo do autor).

Nessa perspectiva, as instituições que "conservam a tradição de práticas 
colecionistas, de ciências museológicas/diagnósticas [...] constituem-se em poderosas instituições de controle de políticas, de concepções científicas, de práticas comunicacionais" (LOPES; HEIZER, 2011, p. 11). Aline Azevêdo (1992) falando das coleções do Museu Paraense Emílio Goeldi destaca que os profissionais da informação devem ficar atentos para a importância de se trabalhar com tratamento de dados que não sejam necessariamente bibliográficos como um enfrentamento e um desafio profissional.

Para além do resguardo da memória, essas atividades colecionistas podem auxiliar no processo de reconhecimento e validação de saberes locais que podem auxiliar no trato da preservação da natureza. Essas práticas colecionistas na área de preservação da biodiversidade estão presentes no estado do Tocantins.

A região hoje conhecida como Tocantins fora parte do estado de Goiás antes da promulgação da Constituição do Brasil de 1988. O movimento separatista teve início ainda no período colonial brasileiro (1500-1822). Com um alvará de D. João VI a região de Goiás, que já possuía uma Comarca com sede em Vila Boa, atual Cidade de Goiás, ou Goiás Velho, ganha outra, a Comarca do norte, com sede provisória em Natividade, no atual território do Estado do Tocantins (NASCIMENTO, 2011). Passando pela Colônia, pelo Império e pela República, o estado do Tocantins foi sendo reelaborado. Até que no dia $1^{\circ}$ de janeiro de 1989 instalou-se, em decorrência da nova Constituição Federal, o Estado do Tocantins. Possui 277. $621 \mathrm{~km} 2$ de área territorial, com dois rios importantes para o Brasil: Tocantins e Araguaia; a maior ilha fluvial do mundo (Ilha do Bananal) e enorme biodiversidade representada por suas ricas fauna e flora.

A Universidade Federal do Tocantins (UFT) foi criada com a Lei 10.032 de 23 de outubro de 2000 e regulamentada pelo Decreto 4.279 de 21 de junho de 2002. Seu primeiro reitor foi, após aprovação em consulta pública pela "comunidade acadêmica", nomeado pelo Vice-Presidente da República José de Alencar em 20 de agosto de 2003. A UFT possui 18.881 alunos, 50 cursos de graduação, 7 campi (Araguaína, Arraias, Miracema, Palmas, Porto Nacional, Gurupi e Tocantinópolis) e oito bibliotecas, uma em cada campus, sendo que 
em Araguaína são duas, 21 programas de mestrado e 5 de doutorado e conta com 2.659 servidores (933 professores e 1.726 técnicos administrativos) (UNIVERSIDADE FEDERAL DO TOCANTINS, 2015b, passim).

Porto Nacional é uma das cidades mais antigas do Tocantins. Foi fundada em 1738 pelos bandeirantes na busca pelo ouro; fica às margens do Rio Tocantins e possui, de acordo com o censo de 2014, mais de 50 mil habitantes. O campus da UFT nesta cidade possui cursos de graduação (Ciências Biológicas, Ciências Sociais, Geografia, História, Letras, com três habilitações, e Relações Internacionais) e também cursos de pós-graduação lato e stricto sensu. As Coleções Biológicas, em sua maioria, estão presentes neste campus: zoologia, paleontologia e herbário.

Nas coleções biológicas, acessíveis a toda comunidade científica,

Destaca-se a função de repositório de material testemunho de múltiplas áreas das Ciências Biológicas, especialmente de ecologia e projetos aplicados (estudos de impacto ambiental, documentação de espécies ameaçadas e espécies invasoras, monitoramento de [projetos] ambientais, estudos parasitológicos, monitoramento pesqueiro [...] (UNIVERSIDADE FEDERAL DO TOCANTINS, 2005).

Além de difundir os conhecimentos da biodiversidade do Estado, tais coleções visam, também, a conscientização da "população para a importância da conservação de seu patrimônio biológico" (UNIVERSIDADE FEDERAL DO TOCANTINS, 2015c, p. 32). Coleções científicas são capazes de representar a biodiversidade local com a finalidade de estudos/pesquisas e educação/conscientização da população para a necessidade de preservação da fauna e da flora, bem como os fósseis. Dessa maneira, a popularização e a disseminação das informações desses registros podem ajudar no desenvolvimento da cultura de preservação da natureza para além do desenvolvimento sustentável. 


\section{COLEÇÕES BIOLÓGICAS NOS CATÁLOGOS DAS BIBLIOTECAS UNIVERSITÁRIAS: UMA PROPOSTA APROXIMATIVA}

A integração dos metadados dos itens das coleções biológicas da UFT nos catálogos das bibliotecas da mesma instituição de ensino superior pode ser de grande ajuda no processo de construção de saberes com, e não simplesmente saberes sobre (PORTO-GONÇALVES, 2006) os ecossistemas tocantinenses. Assim, as atuações social, econômica, institucional, ecológica, espacial e cultural podem ser preservadas não com a lógica de mercado para desenvolver um país, mas pela lógica da natureza não centrada na humanidade exploradora.

Como pode se dar essa integração? Por meio do repositório institucional ou de seu catálogo online, a biblioteca universitária pode dar visibilidade às pesquisas que prezem a preservação da natureza integrando os metadados dos registros dessas coleções biológicas. A maioria dessas coleções já está passando por um processo de digitalização de seus acervos/registros. O que propomos aqui é uma complementação dessas práticas de maneira a atuar em conjunto visando à expansão da atuação dos profissionais da informação para além dos materiais bibliográficos (AZEVÊDO, 1992).

Qualquer usuário/a, ou membro da comunidade científica local, regional, nacional ou internacional poderá ter acesso a informações de coleções biológicas de uma maneira mais rápida e efetiva. Deve haver também a discussão sobre o que pode e o que não pode ser divulgado amplamente: seja por questões de biossegurança ou segurança nacional ou do Estado (GONZALEZ, 2010).

Assim, a biblioteca ajuda na construção de saberes locais. Isso pode ser uma excelente atitude para a promoção de práticas ambientalmente contextualizadas para além do desenvolvimento sustentável; para além da manutenção de um sistema explorador, ajudando na construção de novas possibilidades para solução de problemas complexos.

Ressaltamos que a disposição dos próprios registros das coleções, por meio de repositório institucional, ou somente os metadados desses registros 
nos catálogos das bibliotecas é uma decisão a ser tomada pelas instâncias superiores da universidade.

Apontamos duas possibilidades para esta integração: somente os metadados dos registros das coleções biológicas, ou o registro inteiro, fotografado, por exemplo. No primeiro caso basta inserir na base de dados dos catálogos das bibliotecas os metadados das coleções biológicas como, por exemplo, nome científico, nome popular e localização do item; assim o usuário iria à busca do item a ser estudado. No segundo caso, poderia ser utilizado Repositório Institucional para disponibilizar os registros fotográficos, por exemplo, dos itens colecionados.

Acreditamos que a ação de integrar os metadados dos registros das coleções biológicas pelas bibliotecas universitárias pode contribuir com a desconstrução de hierarquizações logocêntricas, como nos mostrou Jacques Derrida (DERRIDA, 1999; GOULART, 2003). Essas hierarquizações dizem o que é certo e o que é errado em matéria de saberes ou de des-envolvimentos quando separa quem é e quem não é desenvolvido pela lógica perversa do capital que continua explorando e destruindo agora maquiado pela égide do "desenvolvimento sustentável".

\section{CONSIDERAÇÕES FINAIS}

A utilização da natureza é necessária para a sobrevivência das espécies, não somente de uma, mas de todas. Com essa ideia em mente, a humanidade deve ter a consciência de que a permanência e posteridade depende da utilização dos recursos naturais. Entretanto, esta não é a única condição que determina ser ambientalmente responsável. Desenvolvimento sustentável, sustentabilidade institucional e ecologia da informação são expressões que estão ganhando espaço no cotidiano dos profissionais da informação. Mas tem ganhado também a devida crítica?

Como ressaltou o Relatório Brundtland (1987) o problema ambiental não diz respeito somente ao uso dos recursos naturais renováveis ou não, mas perpassa as questões da desigualdade social, do acesso aos bens de 
consumo, e de itens elementares à vida: educação, saúde, segurança, saneamento básico.

Ações de economia de água, reciclagem de materiais, economia de energia elétrica, utilização de energia "limpa", ou qualquer outra atividade dita como "sustentável" pode ajudar no respeito à natureza, mas não se pode pensar simplesmente que essas ações atendem à real necessidade de justiça social e ambiental. Antes devem ser percebidos os interesses por trás dessas propostas ditas de "desenvolvimento sustentável". A quem interessam e por quê?

Aqui foi proposta uma integração dos metadados dos registros das coleções biológicas nos catálogos das bibliotecas da Universidade Federal do Tocantins. Sua finalidade seria de construção de conhecimentos locais como uma forma de articulação de ações ambientalmente contextualizadas para além do desenvolvimento sustentável. Pois só a construção de saberes com são capazes de minar a neurose humana dos saberes sobre (MAIA; SANTOS, 2015; PORTO-GONÇALVES, 2006).

Essa crítica deve ser feita com coragem nas práticas cotidianas. Devese ter em mente que a ação feita com consciência pode ajudar na não aceitação de um novo colonialismo (LINO et al., 2005). Denominando essa nova dominação mundial de crescimento, desenvolvimento com a falsa pretensão de proteção do "meio ambiente"; conceito este que descentralizou a ideia de natureza e monopolizou o homem como única espécie detentora e autorizada pela "ciência verdadeira" a dominar e explorar o que não the foi dado, mas sim tomado à força. Nesse novo colonialismo os países "desenvolvidos" ditam as regras do desenvolver-se e os que não as seguem serão punidos. É possível mudar essa realidade?

\section{REFERÊNCIAS}

AZEVÊDO, Aline. Tratamento da informação em coleções científicas de Zoologia. Ciência da Informação, Brasília, v. 21, n. 1, p. 59-61, jan./abr. 1992.

BOGDAN, Robert; BIKLEN, Sari. Qualitative research for education: an introduction to theories and methods. Boston: Allyn e Bacon, 2006. 
BRUNDTLAND, Gro Harlem. Our common future. Nova York: ONU, 1987.

Disponível em: <http://www.un-documents.net/wced-ocf.htm>. Acesso em: 23 mar. 2016

BELLESI, Lia; SILVA, Ana Rosa. A informação ambiental em sistema cooperativo automatizado: o Siamaz. Ciência da Informação, Brasília, v. 21, n. 1, p. 69-71, jan./abr. 1992.

CARDOSO, Nathalice. A contribuição do bibliotecário para a educação ambiental. Perspectivas em Ciência da Informação, v. 15, n. 2, p. 140-162, maio/ago. 2010.

CASTRILLON, Silvia. Biblioteca escolar: un modelo legitimista o una propuesta transformadora? Lectura y vida, La Plata, Argentina, v. 30, n. 4, diciembre, 2009. Disponível :<http://www.lecturayvida.fahce.unlp.edu.ar/numeros /a30n4/30_04_Castrillon.pdf/view?searchterm=castrillon>. Acesso em: $18 \mathrm{dez}$. 2015.

COSTA, Heloísa. Meio ambiente e desenvolvimento: um convite à leitura. In: HISSA, Cássio (Org.). Saberes ambientais: desafios para o conhecimento disciplinar. Belo Horizonte: Ed. UFMG, 2008. p. 79-107.

CUNHA, Murilo Bastos da. A biblioteca universitária na encruzilhada.

DataGramaZero, Brasília, v. 11, n. 6, dez. 2010. Disponível em: <http://www.dgz.org.br/dez10/Art_07.htm>. Acesso em: 22 dez. 2015.

DAVENPORT, Thomas. Ecologia da informação. São Paulo: Futura, 1998.

DERRIDA, Jacques. Gramatologia. São Paulo: Perspectiva, 1999.

DOLABELA, Regina Froes; BEMFICA, Juliana do Couto. A produção de informação sobre o meio ambiente no Brasil: condicionantes técnicos, sociais e políticos. In: ENCONTRO NACIONAL DE PESQUISA EM CIÊNCIA DA INFORMAÇÃO, 7., 2006, Marília, SP. Anais eletrônicos... Marília, SP: PPGCI, 2006.

ECOLOGY. In: Britannica Academic. Disponível em: <http://academic-ebbritannica.ez6.periodicos.capes.gov.br/EBchecked/topic/178273/ecology>. Acesso em 20 abr. 2016.

GONZALEZ, Marcos. Análise das restrições de acesso a dados de espécies ameaçadas, previstas em políticas de coleções biológicas científicas brasileiras, á luz do direito ambiental e da ciência da informação. Ciência da Informação, Brasília, DF, v. 39, n. 1, p. 33-50, jan./abr. 2010.

GOULART, Audemaro. Notas sobre o desconstrucionismo de Jacques Derrida. 2003. Disponível em: <http://www.pucminas.br/imagedb/mestrado_doutorado/publicacoes/PUA_ARQ ARQUI20121011175312.pdf>. Acesso em: 28 mar. 2016. 
JOHNSON, Hazel; WILSON, Gordon. Institutional sustainability: community and waste management in Zimbabwe. Futures, v. 3, p. 301-316, 2000.

KAYAGA, Sam; MUGABI, Josses; KINGDOM, William. Evaluating the institutional sustainability of an urban water utility: a conceptual framework and research directions. Utilities Policy, Guildford, v. 27, p. 15-27, 2013.

LANKES, David. Expect more: demanding better libraries for today's complex world. 2012. Disponível em: <www.davidlankes.org>. Acesso em: 22 dez. 2015.

LAROCA, Sebastião. Ecologia: princípios e métodos. Petrópolis, RJ: Vozes, 1995.

LIMA; Telma; MIOTO, Regina. Procedimentos metodológicos na construção do conhecimento científico: a pesquisa bibliográfica. Revista Katálysis, Florianópolis, v. 10 n. esp., p. 37-45, 2007.

LINO, Geraldo et al. Ambientalismo: novo colonialismo. Rio de Janeiro: Capax Dei, 2005.

LOPES, Maria; HEIZER, Alda (Org.). Colecionismos, práticas de campo e representações. Campina Grande, PB: Eduepb, 2011. Disponível em: <http://books.scielo.org/id/rk6rq>. Acesso em: 23 mar. 2016.

LOZANO, Marisa; ZAFALON, Zaira; COSTA, Luzia. Contribuição do bibliotecário como educador ambiental: o caso da unidade de gestão de resíduos da Universidade Federal de São Carlos. In: CONGRESSO BRASILEIRO DE BIBLIOTECONOMIA, DOCUMENTAÇÃO E CIÊNCIA DA INFORMAÇÃO, 23., Anais..., Bonito, MS, 2009.

MAIA, Marcos; SANTOS, Larissa. Registro de memórias locais na biblioteca escolar: um olhar para o livro artesanal. Revista Interface, v. 10, n. 10, p. 7995, dez. 2015. Disponível em: <https://sistemas.uft.edu.br/periodicos/ index.php/interface/article/view/1951>. Acesso em: 25 mar. 2016.

MATHIAS, Armin. Instrumentos para o desenvolvimento sustentável regional. Revista do Centro de Estudos Administrativos e Contábeis, Belém, v. 2, n. 2, p. 19-30, 2001. Disponível em: <http://www.ufpa.br/amazonia21/publicacoes/ armin/Instrumentos.pdf>. Acesso em: 25 mar. 2016.

NASCIMENTO, Júnio. Tocantins: história e geografia. Goiânia: Bandeirante, 2011.

PAYNE, Philip et al. Promoting green issues and sustainability in UK higher education libraries. SCONUL Focus, London, v. 42, p. 57-60, 2007. Disponível em: <http://eprints.leedsbeckett.ac.uk/579/8/Promoting_green_issues.pdf>. Acesso em: 25 mar. 2016. 
PORTO-GONÇALVES, Carlos. A globalização da natureza e a natureza da globalização. Rio de Janeiro: Civilização Brasileira, 2006.

PUTMAN, Robert. Comunidade e democracia: a experiência da Itália moderna. Rio de Janeiro: FGV, 2005.

SÁ-SILVA, Jackson; ALMEIDA, Cristóvão; GUINDANI, Joel. Pesquisa documental: pistas teóricas e metodológicas. Revista Brasileira de História \& Ciências Sociais, São Leopoldo, v. 1, n. 1, jul. 2009.

SPANGENBERG, Joachim; PFAHL, Stefanie; DELLER, Kerstin. Towards indicators for institutional sustainability: lessons from an analysis of Agenda 21. Ecological Indicators, v. 2, p. 61-77, 2002.

TEIXEIRA, Sebastião Nizio. Sustentabilidade institucional. Disponível em: <http://www.emater.go.gov.br/w/1302>. Acesso em: 23 mar. 2016.

UNIVERSIDADE FEDERAL DO TOCANTINS. Resolução n. 7, de 15 de abril de 2015 do Conselho Universitário. Palmas, 2015a.

UNIVERSIDADE FEDERAL DO TOCANTINS. Relatório de avaliação institucional - Ano 2014. Palmas: EDUFT, 2015b.

UNIVERSIDADE FEDERAL DO TOCANTINS. Resolução n. 27, de 19 de novembro de 2015: dispõe sobre a criação e implantação do Instituto de Biodiversidade do Tocantins. Palmas, 2015c.

UNIVERSIDADE FEDERAL DO TOCANTINS. Resolução CONSEPE n. 11, de 12 de agosto de 2005: dispõe sobre a criação do Núcleo de Estudos Ambientais (campus de Porto Nacional) da UFT. Palmas, 2005.

VIEIRA, Anna. Informação para gerenciamento ambiental no Brasil. Revista da Escola de Biblioteconomia da UFMG, Belo Horizonte, v. 9, n. 2, p. 177-194, set. 1980.

VIEIRA, Anna. Meio ambiente e desenvolvimento sustentável: fontes para compreensão do discurso político-ambiental do governo brasileiro. Ciência da Informação, Brasília, v. 21, n. 1, p. 7-13, jan./abr. 1992.

\section{BIOLOGICAL COLLECTIONS AND ACADEMIC LIBRARIES: A PROPOSAL BEYOND SUSTAINABLE DEVELOPMENT}

ABSTRACT 
Introduction: Environmentalism and ecology have gained ground in the discussions and in the daily practices of university libraries. Objective: To describe the importance of integrating metadata records of biological collections in the catalogs of libraries of UFT as an action "environmentally contextualized" beyond sustainable development. Methodology: descriptive and explanatory research with a qualitative approach with data collection through bibliographical and documentary research. Theoretical reading through Jacques Derrida's deconstructionism. Results: The concepts of sustainable development, institutional sustainability and information ecology have been used by information professionals in an uncritical manner, without regard to its marketing perspective and maintaining the operating system of exploration of the nature. Conclusions: if informational professionals intend to participate in the concern/preservation for nature should be alert to develop actions beyond sustainable development. Should help local knowledge construction process and help in building information utilization through their daily practices.

Descriptors: Academic library. Biology. Information Organization Library catalog. Metadata.

\title{
COLECCIONES BIOLÓGICAS Y BIBLIOTECAS UNIVERSITÁRIAS: UMA PROPUESTA ALLÁ DEL DESARROLLO SOSTENIBLE
}

\begin{abstract}
RESUMEN
Introducción: Ambientalismo y la ecología han ganado terreno en los debates y en las prácticas cotidianas de las bibliotecas universitarias. Objetivo: describir la importancia de integrar los registros de metadatos de colecciones biológicas en los catálogos de las bibliotecas de la UFT como una acción "con el medio ambiente contextualizada" más allá de un desarrollo sostenible. Metodología: investigación descriptiva y explicativa con un enfoque cualitativo con la recolección de datos a través de la investigación bibliográfica y documental. Lectura teórica a través de la deconstrucción de Jacques Derrida. Resultados: Los conceptos de desarrollo sostenible, la sostenibilidad institucional y la ecología de la información han sido utilizados por los profesionales de información de una manera acrítica, sin tener en cuenta su perspectiva de la comercialización y el mantenimiento del sistema explorativo de la naturaleza. Conclusiones: si los profesionales de información tienen la intención de participar en la preocupación por la naturaleza deben estar alertas para desarrollar acciones más allá de un desarrollo sostenible. Debería ayudar a proceso de construcción del conocimiento local y ayuda en la construcción de modos de uso de la información a través de sus prácticas diarias.
\end{abstract}

Descriptores: Biblioteca universitaria. Biologia. Catálogo. Metadatos. Organización de la información. 